\title{
Shear Zone Treatment at Dam Foundation Level
}

\section{Ashutosh Anand, Somesh Kumar, Vivek Tripathi}

Designs \& Research Wing, Central Water Commission, New Delhi, India

\section{Email address:}

somesh.ce@rediffmail.com (S. Kumar), ashutoshanand-cwc@gov.in (A. Anand)

\section{To cite this article:}

Ashutosh Anand, Somesh Kumar, Vivek Tripathi. Shear Zone Treatment at Dam Foundation Level. American Journal of Civil Engineering. Vol. 5, No. 6, 2017, pp. 352-357. doi: 10.11648/j.ajce.20170506.16

Received: September 14, 2017; Accepted: September 19, 2017; Published: November 6, 2017

\begin{abstract}
Foundation is a critical element for any dam. Understanding the foundation and the required treatment is critical to developing the final dam design. However, the design of the foundation does not end with the final design drawings for the Project. During construction foundation conditions need to be evaluated as excavation and construction proceeds to determine if foundation conditions are consistent with assumptions and expectations. Adjustments to the planned excavation or to the design of the dam, including changes in the grout curtain, dam geometry, and other features are often required during construction. This paper discusses the foundation conditions encountered during construction of concrete gravity dam and the associated treatments that were required. To ensure the safety of project, foundation was treated and design adjustments were made. A 2D analysis was carried out using ABAQUS Finite Element Method (FEM) software.
\end{abstract}

Keywords: Shear Zone, Dam, Foundation Treatment, Abaqus, Geology

\section{Introduction}

The situations is difficult to designer when unexpected geological conditions arise such as sudden variation in rock strata, failure planes and faults in rock etc. This paper discusses about shear zone treatment of a concrete dam which is $86.00 \mathrm{~m}$ high and $213.50 \mathrm{~m}$ long. Foundation level of the dam is $34.5 \mathrm{~m}$ below from the bed level. The shear zone spreads below the overflow blocks 3,4,5,6 and 7 from upstream to downstream of dam axis (Figure 1).

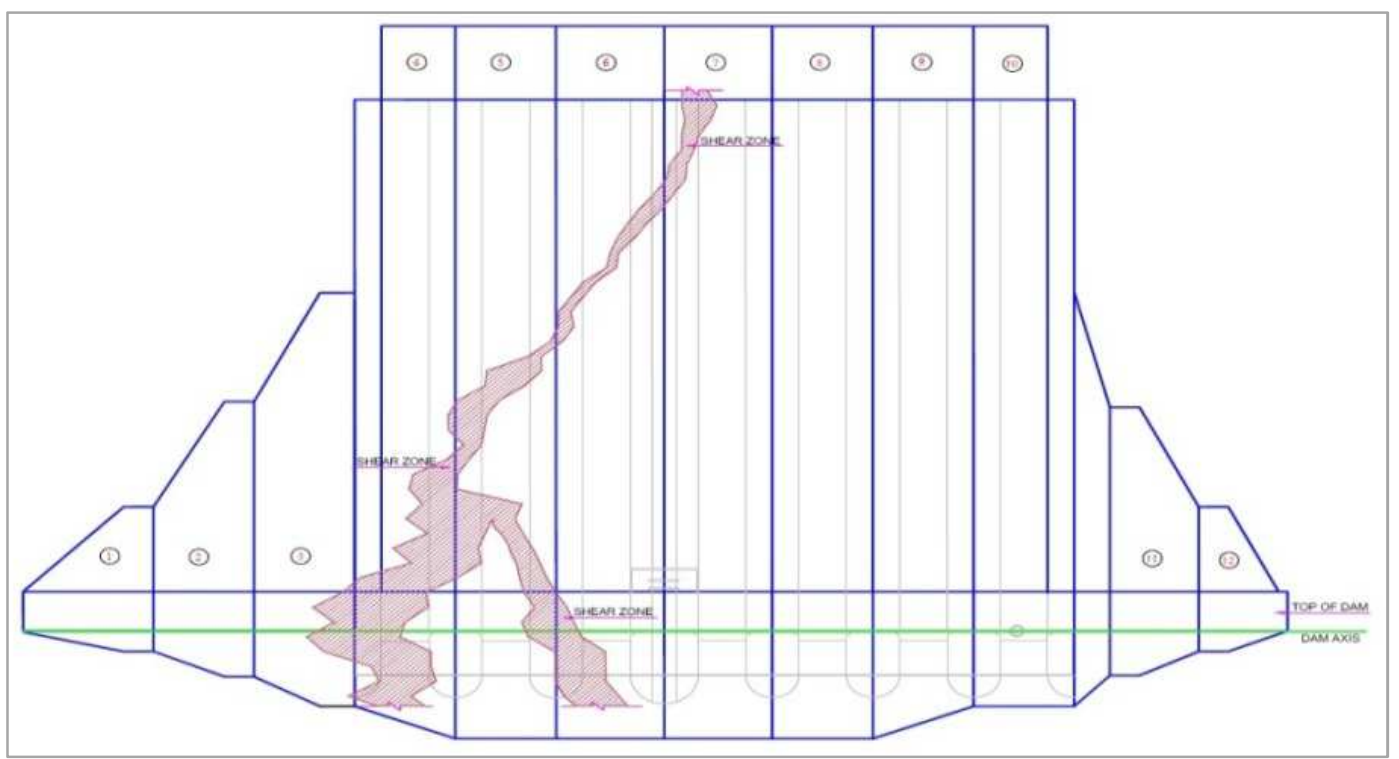

Figure 1. Dam Plan. 


\section{Dam Foundation Geology}

The mapping of the shear zone was carried out simultaneosly with excavation. The exposed rock mass in the shear trench/affected area comprised predominantly of medium to coarse grained Quartzo Feldsphatic Gneiss and Leucogranite with minor pegmatite veins. In the mapped area, the rock mass comes under poor and very poor in shear zone and associated rock mass; and fair class in jointed and blocky rock mass. Two major shear zones were encountered during the mapping of the trench area. The major shear zone is dipping towards left bank side with $15^{\circ}-68^{\circ}$ towards $\mathrm{N} 40^{\circ}$ $80^{\circ}$ direction, with $0.5 \mathrm{~m}$ to $1.5 \mathrm{~m}$ thick crushed rock mass with 10 to $20 \mathrm{~cm}$ thick clay gouge. The affected area of the shear zone is about 1 to $2 \mathrm{~m}$ having highly fractured and jointed rock mass with thin shear seams at places (Figure 2).

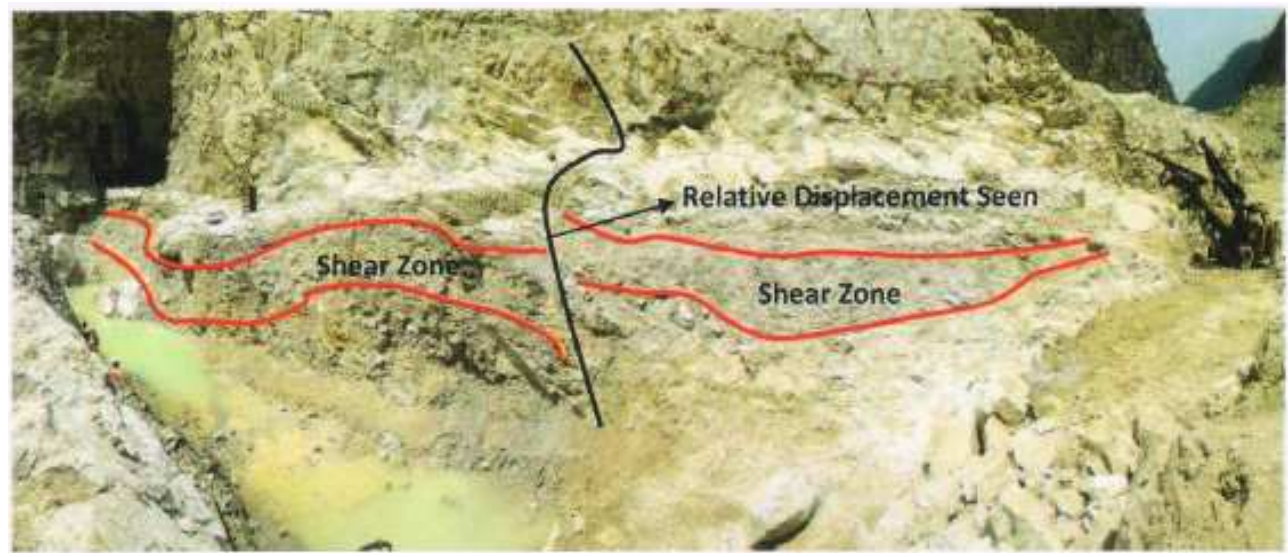

Figure 2. Shear Zone at Left Side of Excavated Trench.

The cover between the competent rock mass and shear zone in the resting bench at left side of the shear trench is about minimum $0.5 \mathrm{~m}$ at dam axis to maximum $2.5 \mathrm{~m}$ at 36 $\mathrm{m} \mathrm{d} / \mathrm{s}$ of the dam axis, the cover between bench and shear zone increases towards hill side due to the dip and dip direction of the shear. Another shear zone dipping towards right bank side with $20-45^{\circ}$ towards $\mathrm{N} 190^{\circ}$ direction, with 0.2 to $0.8 \mathrm{~m}$ thick crushed rock mass with 5 to $10 \mathrm{~cm}$ clay gouge was observed. The affected area of shear zone varies between 0.5 to $1 \mathrm{~m}$ with minor shear seams (Figure 3 ).

After removal of shear material from the trench, the rock is exposed at the base of the trench. In between the two shear zone, the rock mass consist of hard minor fractures at places with minor seams Quartzo Feldsphatic Gneiss. The rock mass is slightly weathered to fresh. It is observed that the shear zone at left side of the excavated trench is pinching towards downstream side and gets bifurcated in upstream portion. The thickness of the shear zone at right side reduces towards downstream side and finally merges with left side major shear zone. The $\mathrm{Q}$ value of the rock mass ranges from 1.5 to 4.5 class IV to III and in the shear zone portion it varies from 0.1 to 0.08 class V. The Rock Mass Rating (RMR) varies in jointed and blocky rock mass from 20 to 45 and GSI varies 15 to 40 where as in shear zone RMR ranging from 10 to 15 and Geological Survey of India (GSI) 5 to 10.

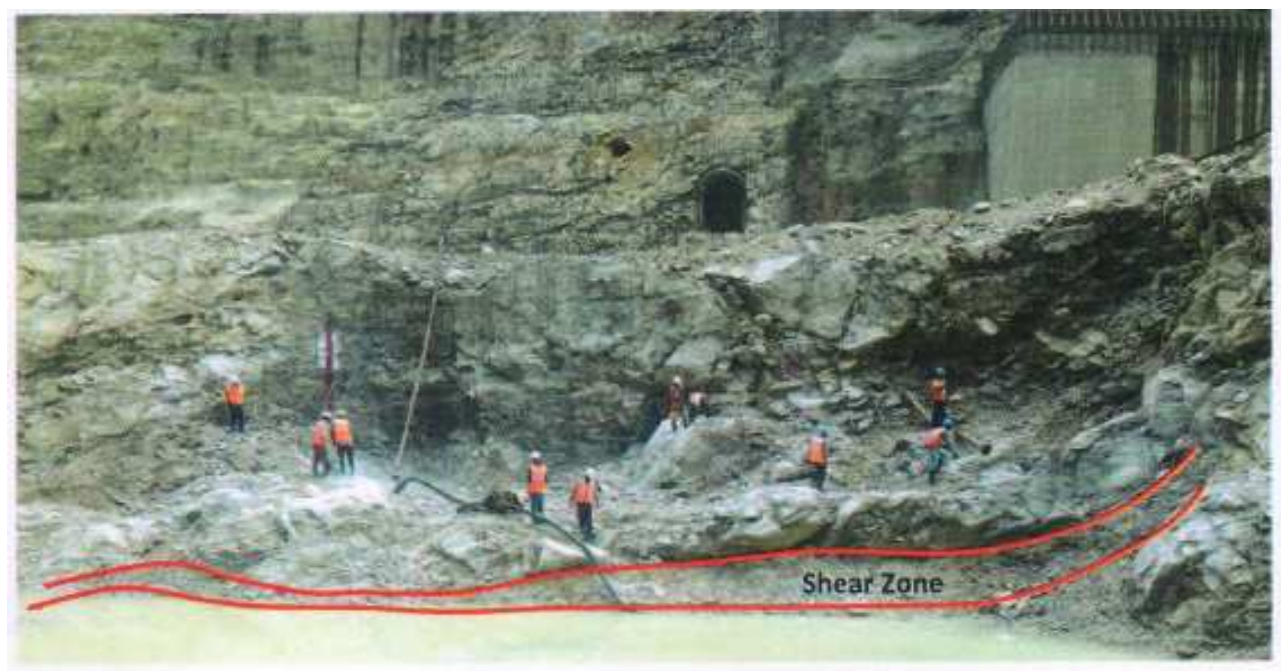

Figure 3. Shear Zone Right Side of Excavated Trench. 


\section{Dental Treatment for Shear Zone}

Very often the exploratory drilling or final excavation uncovers faults, seams, or shattered or inferior rock extending to such depths that it is impracticable to attempt to clear out such areas entirely. These conditions require special treatment in the form of removing the weak material and backfilling the resulting excavations with concrete. This procedure of reinforcing and stabilizing such weak zones is frequently called "dental treatment." [2]

\subsection{Depth of Excavation of Weak Zone}

All the weak material along the length of shear zone has been excavated to the depth ' $d$ ' i.e reinforecd slab + concrete plug (shown in Figure 4) which were decided as per theortical studies made by United State Bureau of Reclamation (USBR) in connection with foundation problem encountered at Shasta and Friant dams, have led to the development of the following approximate equations for determination of depth of treatment of transverse seams.

$$
\mathrm{d}=0.3 \mathrm{~b}+1.524(\text { for } \mathrm{H}<46 \mathrm{~m})
$$

Where,

$\mathrm{H}=$ height of dam above general foundation level in meteres;

$\mathrm{b}=$ width of weak zone in meteres;

$\mathrm{d}=$ depth of excavation of weak zone below surface adjoining sound rock in meteres.

These rules provide a means of approach to the question of how much should be excavated, but final judgment must be exercised in the field during actual excavation operations [1]. Since the width of shear zone is more at some places approximate $50 \mathrm{~m}$. Therefore, reinforced concrete slab was proposed at foundation level. The above guide lines could not be followed due to large width of shear zone. So, slab was designed by analysing the shear zone behavior by FEM.

\subsection{Cutting}

The cutting profile with stable rock slopes provided at the shear zone affected area (Figure 4).

$$
\mathrm{D}=0.00656 \mathrm{bH}+1.526(\text { for } \mathrm{H}>46 \mathrm{~m})
$$

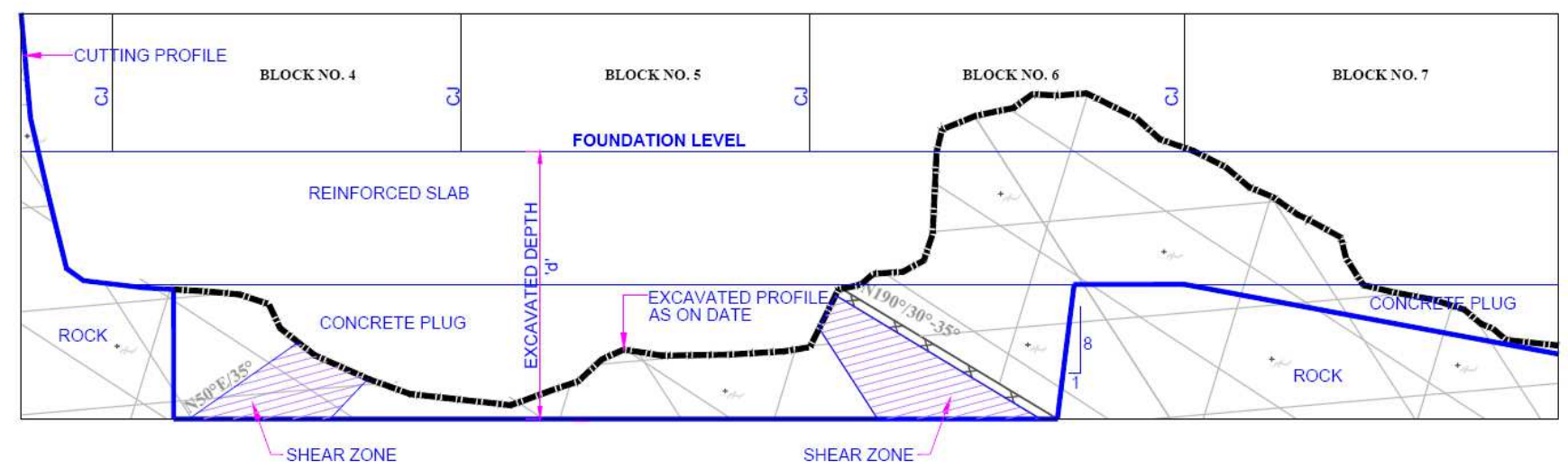

Figure 4. Cutting Profile at Shear Zone Affected Area.

\subsection{Consolidation Grouting}

Consolidation Grouting is carried out in the zone surrounding the shear zone, for filling up the joints/cracks/crevices etc. and there by making the foundation bedrock stronger and less pervious. The consolidation grouting has been provided upto the depth of $10 \mathrm{~m} @ 3 \mathrm{~m} \mathrm{c} / \mathrm{c} .[3]$

\subsection{Contact Grouting}

Contact Grouting is provided to fill up the shrinkage gap and voids, if any, between reinforced concrete slab and plain concrete slab/rock and/or between plain concrete slab and fractured rock/shear zone. [4]

\section{Modelling}

Though the problem is 3-D but due to simplicity a 2-D elastic static analysis has been performed taking conservative approach assuming the plain strain condition along the shear zone from upstream to downstream and considering uniform maximum pressure from the dam blocks, which is experienced on heel/toe of the blocks. A 2-diamensional concrete slab have been modeled which consist of surrounding rock, fractured rock and shear zone in ABAQUS/CAE. While modeling no interface elements were considered. The entire model was modeled as a continuum and then it was partitioned to assign different material properties. In the model the concrete slab was divided on the basis of grade of concrete. The top portion of concrete slab was assigned grade of M25 and bottom portion of concrete slab was assigned grade of M20. The 2D model (Figure 5). 


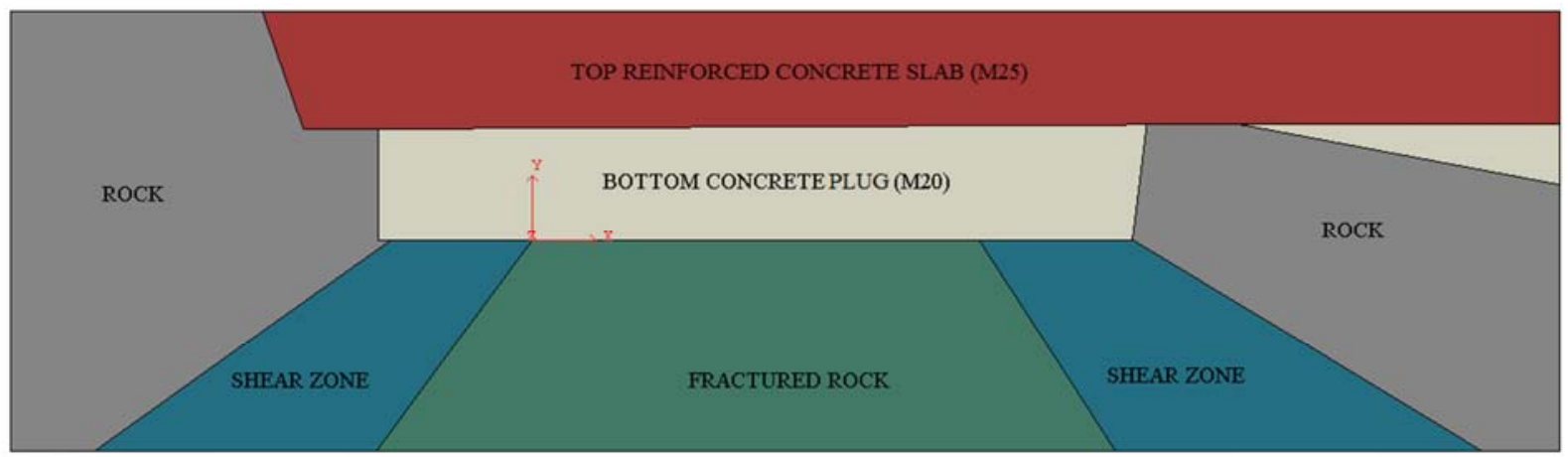

Figure 5. Two Dimensional Finite Element Model.

\subsection{Material Properties}

The materials properties have been used in the modeling are presented in Table 1. The materials were considered to be isotropic and homogeneous in nature.

Table 1. Material Properties.

\begin{tabular}{lllll}
\hline \multirow{2}{*}{ S. No. } & \multirow{2}{*}{ Material } & Property & & \\
\cline { 3 - 4 } & & Density $\left(\mathbf{K g} / \mathbf{m}^{\mathbf{3}}\right)$ & Young's Modulus $\left(\mathbf{N} / \mathbf{m}^{2}\right)$ & Poisson's Ratio \\
\hline 1. & Top Reinforced Concrete Slab (M25) & 2500 & $2.50 \times 10^{10}$ & 0.18 \\
2. & Bottom Concrete Plug (M20) & 2400 & $2.23 \times 10^{10}$ & 0.18 \\
3. & Shear Zone & 0 & $2.00 \times 10^{8}$ & 0.35 \\
4. & Rock & 0 & $3.90 \times 10^{9}$ & 0.25 \\
5. & Fractured Rock & 0 & $2.05 \times 10^{9}$ & 0.30 \\
\hline
\end{tabular}

\subsection{Loading}

The loads applied to the model consists of only static loading. The static loads are dead weight of concrete slab and the load of the dam coming over the concrete slab due to the worst combination of Gravity, Hydrostatic, Silt, Uplift, Hydrodynamic and Seismic forces acting on the dam as per IS 6512:1984 [6]. The load of the dam due to various combinations was found to be maximum in Case E (Full reservoir level, normal weather tail water, normal uplift, silt and earthquake) and was applied as a pressure load of $2.05 \mathrm{x}$ $10^{6} \mathrm{~N} / \mathrm{m}^{2}$.

\subsection{Boundary Condition}

The bottom edge of the model was restrained in translation in the vertical as well as horizontal direction whereas the side edges were restrained in translation only in horizontal direction and were free for movement in vertical direction (Figure 6).

\subsection{Meshing of Model}

The model was meshed using 8-noded second order plane strain quad element CPE8 (Figure 6). The meshing was done using free meshing technique.

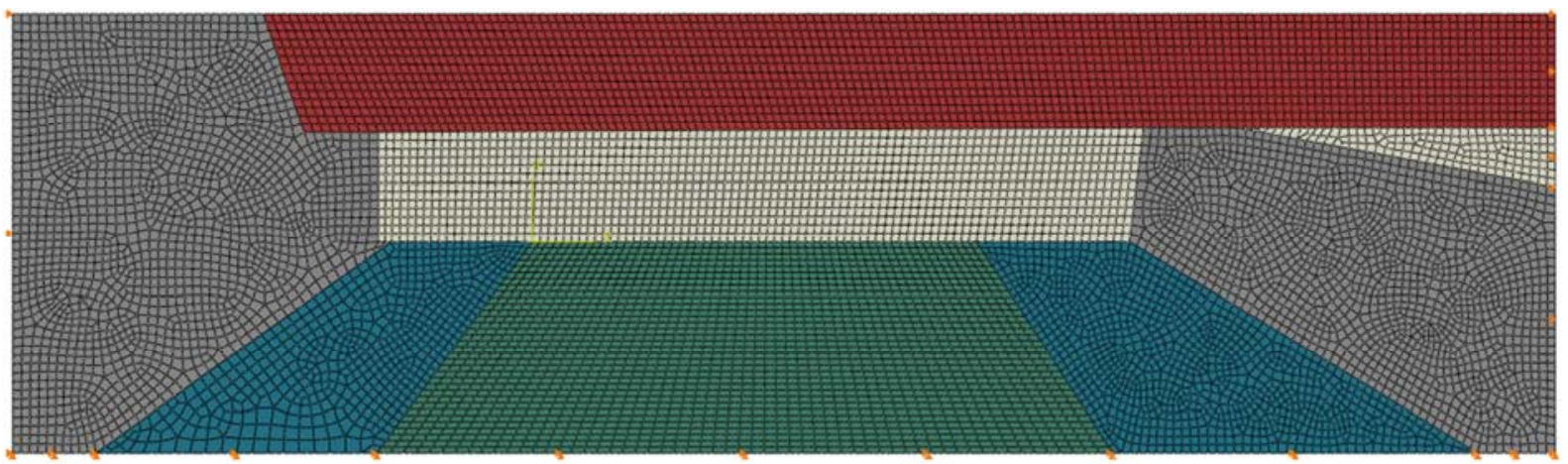

Figure 6. Meshed Model of the Structure.

\section{Results}

The maximum principal stress contour plot (Figure 7) shows that the maximum tensile stress is coming over the top of slab and it reduces with the depth of slab. 


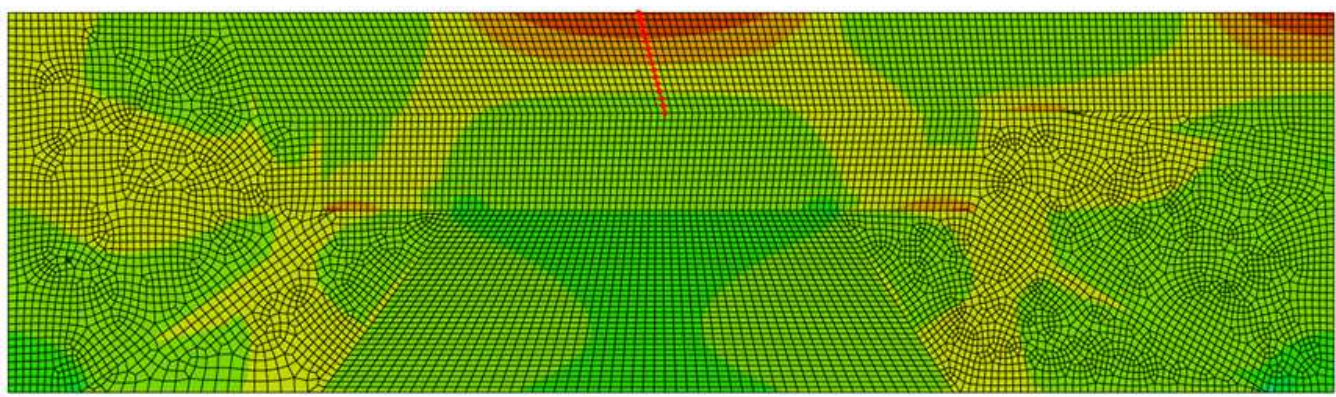

S, Max. Principal (Avg: $75 \%$ )

$+2.671 \mathrm{e}+06$

$+1.946 \mathrm{e}+06$

$+1.221 \mathrm{e}+06$

$+4.965 \mathrm{e}+05$

$-2.283 e+05$

$-9.531 \mathrm{e}+05$

$1.678 \mathrm{en}$

$-2.403 \mathrm{e}+06$

$-3.128 \mathrm{e}+06$

$-3.853 e+06$

$-4.577 \mathrm{e}+06$

$-5.302 \mathrm{e}+06$

Figure 7. Maximum Principal Stress Contour.

The value of the maximum tensile stress $2.67 \mathrm{MPa}$ decreases from the top and becomes zero at a depth of $4.7 \mathrm{~m}$ as can be seen from the plot of Maximum principal stress $(\mathrm{MPa})$ vs Distance from top of slab $(\mathrm{m})$ (Figure 8 ) and the plot of Direct stress $(\mathrm{MPa})$ vs Distance from top of slab (m)
(Figure 9). Positive values represent tensile stresses whereas negative values represent compressive stresses. The stress contour shows that almost whole of the top portion of concrete slab is under tension. Therefore, reinforcement is required only in the top portion of concrete slab.

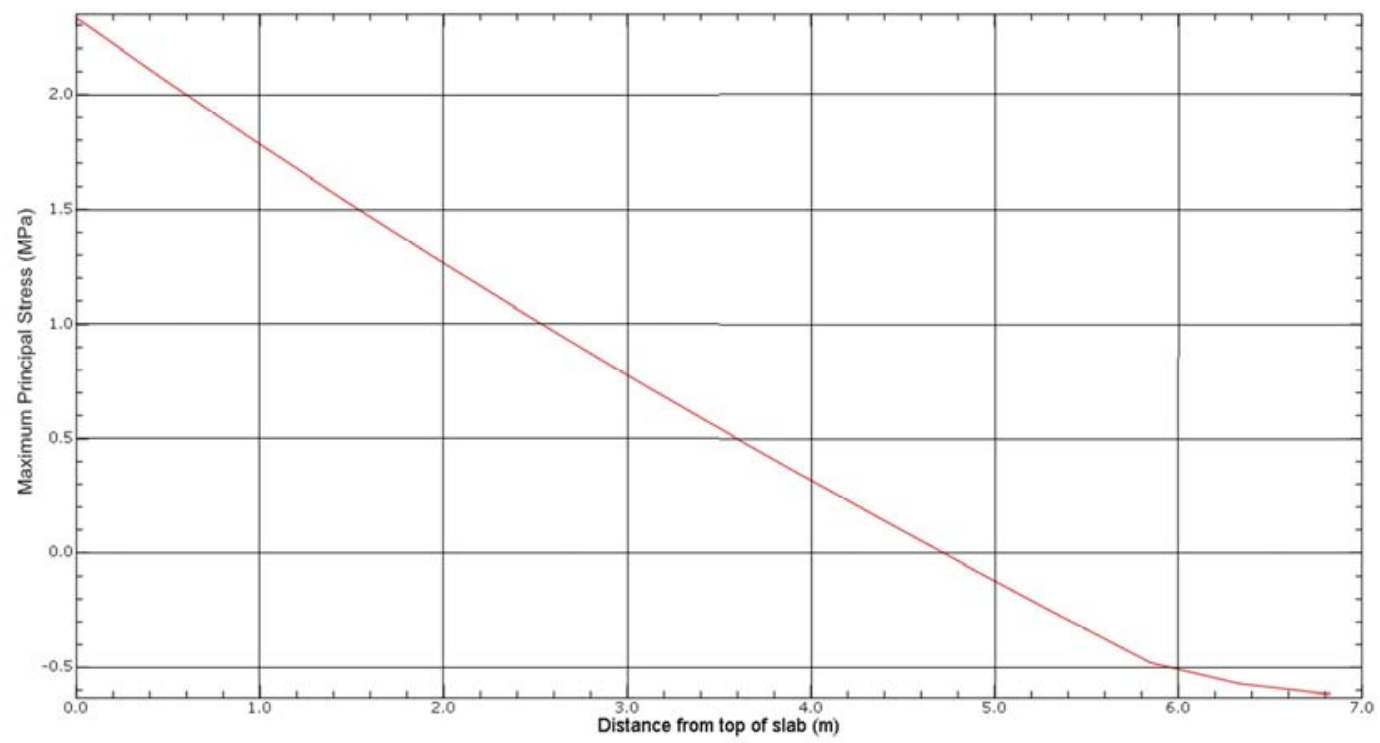

Figure 8. Plot of Maximum Principal Stress, $s_{11}(M P a)$ vs Distance from Top of Slab (m).

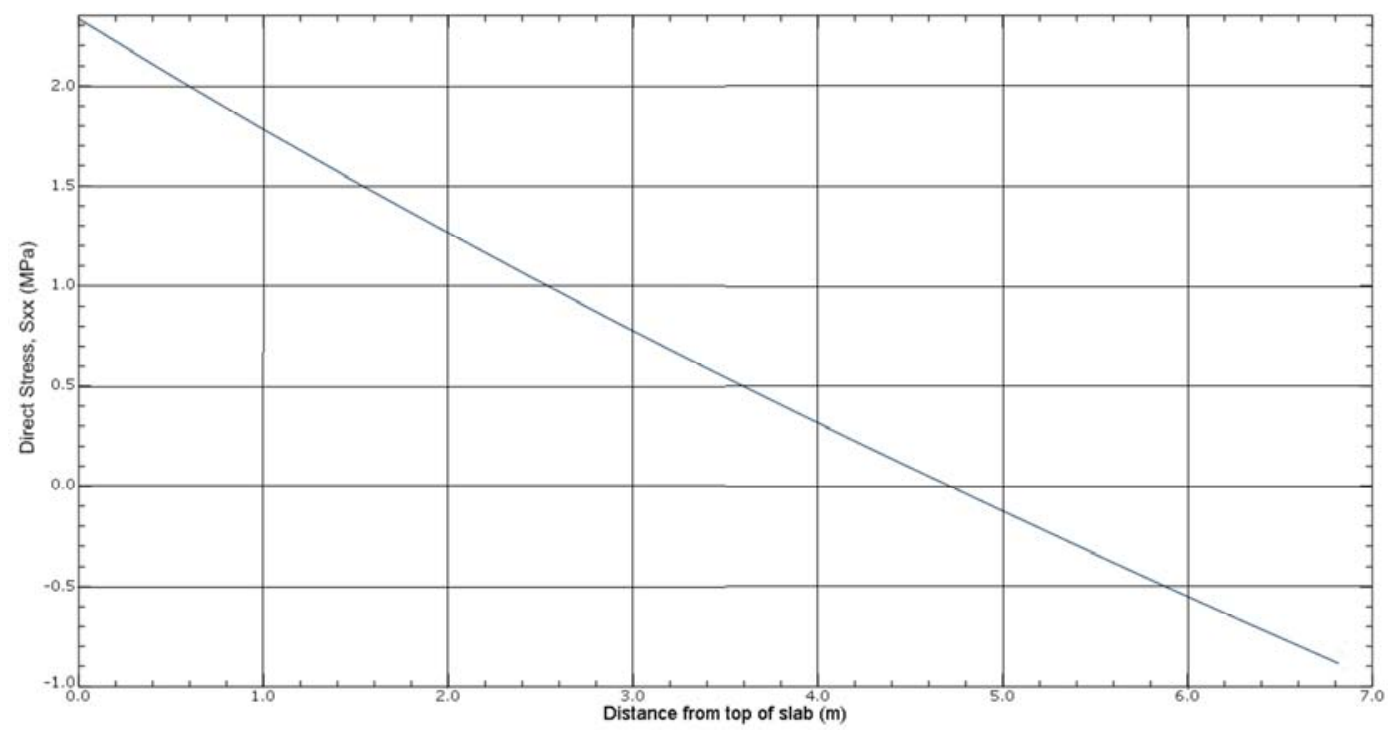

Figure 9. Plot of Direct Stress, $S_{x x}(M P a)$ vs Distance from Top of Slab (m). 


\section{Conclusion}

For safe, timely and economical execution of dam construction, adequate foundation treatment is essential to minimize any kind of post construction problems. The shear zone extending to large depth are encountered during excavation of the foundation, due to such weak zones the load of the structure will be transferred to the firm rock on the two sides. This leads to stress concentrations both in the rock and the structure. The formula for determination of the depth of treatment of shear zone given by USBR is only approximate. Therefore, in the present case where we have two shear zones of large widths at an inclination from horizontal, FEM analysis is required to study the true behaviour of the structure. The reifocement has been provided in the slab according to the direct tensile stresses on the top face of slab coming from the FEM analysis.

\section{References}

[1] Concrete Dams by Dr. H. D. Sharma, Publication No.266, CBIP.

[2] Design Manual of Concrete Gravity Dams, A Water Resources Technical Publication, USBR, Denver, Colorado 1976.

[3] IS: 6066: 1994 (Reaffirmed 2004), Pressure Grouting of Rock Foundation in River Vally Projects - Recommendations.

[4] IS: 5878 (Part VII) - 1972, Code of Practice for Constructing of Tunnels Conveying Water, Part VII Grouting.

[5] IS: 6512 (Reaffirmed 1998), Criteria for Design of Solid Gravity Dams. 